\title{
Thermal-Hydraulic Analysis of Coolant Flow Decrease in Fuel Channels of Smolensk-3 RBMK during GDH Blockage Event
}

\author{
A. Lombardi Costa, M. Cherubini, F. D'Auria, W. Giannotti, and A. Moskalev
}

Received 4 September 2007; Accepted 27 November 2007

Recommended by Ali Hainoun

One of the transients that have received considerable attention in the safety evaluation of RBMK reactors is the partial break of a group distribution header (GDH). The coolant flow rate blockage in one GDH might lead to excessive heat-up of the pressure tubes and can result in multiple fuel channels (FC) ruptures. In this work, the GDH flow blockage transient has been studied considering the Smolensk-3 RBMK NPP (nuclear power plant). In the RBMK, each GDH distributes coolant to 40-43 FC. To investigate the behavior of each FC belonging to the damaged GDH and to have a more realistic trend, one (affected) GDH has been schematized with its forty-two FC, one by one. The calculations were performed using the 0-D NK (neutron kinetic) model of the RELAP5-3.3 stand-alone code. The results show that, during the event, the mass flow rate is disturbed differently according to the power distribution established for each FC in the schematization. The start time of the oscillations in mass flow rate depends strongly on the attributed power to each FC. It was also observed that, during the event, the fuel channels at higher thermal power values tend to undergo first cladding rupture leaving the reactor to scram and safeguarding all the other FCs connected to the affected GDH.

Copyright (c) 2007 A. Lombardi Costa et al. This is an open access article distributed under the Creative Commons Attribution License, which permits unrestricted use, distribution, and reproduction in any medium, provided the original work is properly cited.

\section{INTRODUCTION}

The Reactor Bolshoy Moshchnosty Kanalny (RBMK) is a graphite-moderated boiling water reactor. After the Chernobyl NPP Unit 4 reactor accident, more intensive works have been carried out to increase the safety of the RBMK reactors. The accident showed that the first generation of RBMK design had some serious deficiencies related to its reactivity control and shutdown system. Some of the more significant concerns were about the positive scram effect of the control rods when they were moved down from the topmost position, a large positive void coefficient, and slow insertion of negative reactivity. Efforts have been done in the design to eliminate the possible accident causes and to make this type of reactors safer. Moreover, safety reports have been produced to provide description and analyses of specific accident events connected to the RBMK reactors, for example, those reports mentioned in [1-3].

The results of one important activity concerning RBMK safety have been edited at University of Pisa (UNIPI) based on technical activities performed by N.A. Dollezhal Research and Development Institute of Power Engineering (NIKIET) and UNIPI. The document [4], confidential and restrict, deals with the description of the technical activities con- ducted within the technical assistance for the commonwealth of the independent states (TACIS) project. The activities were focused on the setting-up of a chain of computational tools suitable for the analysis of transients expected in the RBMK NPPs. Among the selected transient scenarios, the partial break of a group distribution header (GDH) has received considerable attention in the safety evaluation of RBMK reactors. The coolant flow rate blocking in one GDH might lead to excessive heat-up of the pressure tubes and can result in multiple fuel channels (FCs) ruptures. Flow rate blockage may occur, for example, due to the blockage of the filter at an inlet of GDH, obstruction of cross section by a shutoff disk of the GDH check valve or GDH accessory, and erroneous closing of the GDH valve.

In this work, GDH flow blockage accident of Smolensk NPP Unit 3 has been simulated. Smolensk is a third generation of RBMK-1000 type constructed in the Russian Federation about $400 \mathrm{Km}$ Southwest of Moscow and it was put into operation on January 17, 1990. RBMK-1000 units have two major distinctions from their counterparts at plants of the second generation: they have no enclosure to receive steam and gas from the reactor cavity and their pressure suppression pool has only one elevation. Some key system data relevant to safety technology are given in Table 1 . 
TABLE 1: Some key parameters of RBMK-1000.

\begin{tabular}{|c|c|c|c|}
\hline Quantity & & Value & \\
\hline \multicolumn{4}{|c|}{ Key-parameters of GDH } \\
\hline Diameter $(\mathrm{mm})$ & & $325 \times 15$ & \\
\hline Length $(\mathrm{mm})$ & & 5400 & \\
\hline Design pressure (bar) & & 100 & \\
\hline Design flow $(\mathrm{t} / \mathrm{h})$ & & 1700 & \\
\hline Total volume of GDH $\left(\mathrm{m}^{3}\right)$ & & 16.5 & \\
\hline \multicolumn{4}{|c|}{ Key-parameters of steam lines } \\
\hline Diameter $(\mathrm{mm})$ & & $76 \times 4$ & \\
\hline Average length (m) & & 32 & \\
\hline Design flow $(\mathrm{t} / \mathrm{h})$ & & 40 & \\
\hline Design pressure (bar) & & 75 & \\
\hline \multicolumn{4}{|c|}{ Key-parameters of DS } \\
\hline Number per reactor & & 4 & \\
\hline DS length $(\mathrm{m})$ & & 30.98 & \\
\hline DS internal diameter $(\mathrm{m})$ & & 2.6 & \\
\hline DS volume $\left(\mathrm{m}^{3}\right)$ & & 150.2 & \\
\hline Operation pressure (bar) & & 68.9 & \\
\hline Design pressure (bar) & & 73.5 & \\
\hline Nominal water level (above the central axis) (mm) & & $380 \pm 50$ & \\
\hline \multicolumn{4}{|c|}{ Key-parameters of core } \\
\hline & Total & Left & Right \\
\hline Power (MW) & 3213 & 1629 & 1583 \\
\hline Flow rate $(\mathrm{Kg} / \mathrm{s})$ & 10118 & 5158 & 5104 \\
\hline Number of FC & 1568 & 794 & 774 \\
\hline Number FC with AA & 90 & 45 & 45 \\
\hline \multicolumn{4}{|c|}{ FC parameters } \\
\hline Full length $(\mathrm{mm})$ & & 18325 & \\
\hline Number of channels & & 1660 & \\
\hline Upper part diameter $(\mathrm{mm})$ & & $95 \times 5$ & \\
\hline Middle part diameter (mm) & & $88 \times 4$ & \\
\hline Lower part diameter (mm) & & $60 \times 5.5$ & \\
\hline Fuel rod overall length (m) & & 3.46 & \\
\hline Active core length (m) & & 6.92 & \\
\hline Spacer/support grids & & 20 per FC & \\
\hline
\end{tabular}

RELAP5 code has been used to perform the transient simulation. This code was originally designed for pressurized water reactors but has been successfully applied, as well as the RELAP5-3D version, for RBMK analyses [4-8].

The transient analyzed consists in the blockage of the coolant mass flow in one GDH. In consequence of this event, the fuel channels (FCs) connected to the blocked GDH remain without coolant. The pressure tube (PT) and the fuel cladding temperatures reach the acceptance criterion (at nominal pressure, i.e., $7 \mathrm{MPa}$ ) few seconds after flow stagnation. The overpassing of this threshold should cause the PT rupture, pressure increase into the reactor cavity and scram generation signal. Hydraulic blockage (i.e., loss of cooling) of one core channel is discussed in [9]. Investigations allowed the evaluation of the consequences of this event that unavoidably causes the rupture of the pressure tube and the radioactivity release to the NPP confinement system (reactor cavity and accident localization system) and to the environment.

The temperature failure criterion in the form of the tube rupture temperature in dependence on the channel pressure has been established for pressure tubes of RBMKs on the basis of experimental data. This dependence varies with the increase in the heating rate. The rupture temperature (in ${ }^{\circ} \mathrm{C}$ ) of the tube varies with pressure (in $\mathrm{MPa}$ ) according to

$$
\begin{array}{ll}
T_{\text {rupture }}=790.5 P^{-0.099} & \text { for heating rates }<1^{\circ} \mathrm{C} / \mathrm{s}, \\
T_{\text {rupture }}=987.7 P^{-0.139} & \text { for heating rates }<1^{\circ} \mathrm{C} / \mathrm{s} .
\end{array}
$$




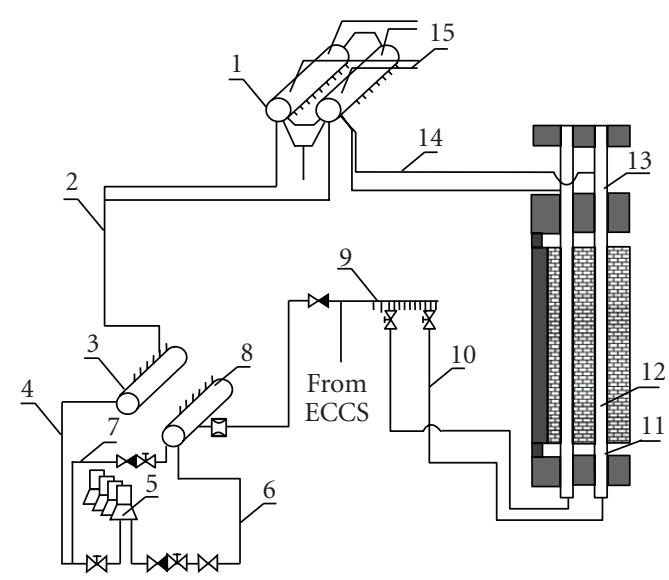

FIgURe 1: RBMK Main Circulation Circuit flow diagram: (1) separator drum (SD), (2) downcomers, (3) suction header (SH), (4)suction piping of the MCP, (5) MCP, (6) pressure piping of the MCP, (7) bypass between headers, (8) pressure header (PH), (9) group distribution header (GDH) with flow limiter, check valve and mixer, (10) water bottom piping, (11) fuel channel before the core, (12) fuel channel within the core, (13) fuel channel above the core, (14) steam water pipes, (15) steam pipelines.

Constant temperature of $650^{\circ} \mathrm{C}$ may be taken as a conservative value of the acceptance criterion for the pressure range from $4 \mathrm{MPa}$ to $8 \mathrm{MPa}$ [3].

\section{RBMK MAIN CIRCULATION CIRCUIT (MCC)}

The MCC flow diagram of the RBMK is shown in the Figure 1 [4]. The main function of each pressure header $(\mathrm{PH})$ is to collect the water that comes from the pressure pipes connected to all main pumps exit and supply the coolant to the twenty-two GDH through twenty-two pipes $(325 \times 15)$ $\mathrm{mm}$. Each pipe has a manual control gate valve, a check valve, and a mixer to mix (in case of accident) the cold water from the emergency core cooling system (ECCS) and the hot water from the MCC. The check valve prevents back-flowing from the fuel channels in case of the failure of the pressure header. Mixers protect the MCC from thermal or hydraulic shocks.

The coolant is supplied to the individual fuel channels via GDH, which are horizontal cylinders. The GDH are securely fastened to support structures to prevent any sliding in case of failure. Each header distributes coolant to 40-43 bottom water pipes. These pipes are provided with isolation and control valves between the GDH outlet and the fuel channel inlet. Isolation and control valves are used to adjust channel flow on the basis of channel power. Flow rates can be controlled by varying the flow area of the valves. This is achieved by manual operation from a separate room in the vicinity of the reactor block.

Therefore, the role of $\mathrm{SH}$ and $\mathrm{PH}$ is to stabilize the coolant flow, as well as the role of GDH is to distribute the flow to the individual FC. Valves are installed in each FC bot- tom line (connecting to GDH) to control the flow and to get uniform values for the FC power/flow-rate ratio. Valves are installed upstream and downstream MCP to isolate the pumps and to allow natural circulation in the loop constituted by FC-outlet, SD, SH, PH, GDH, and FC inlet.

\section{GDH BLOCKAGE EVENT}

Following blockage, the flow rate in the bypass line will depend only on the pressure difference between MCP PH and $\mathrm{GDH}$. At full blocking of GDH, the pressure in accidental GDH becomes approximately equal to pressure in SD. The reactor shutdown signal in case of coolant flow rate reduction, through FC of one GDH, will be generated only in emergency protection against low flow in GDH system [4]. In each of the about $40 \mathrm{GDH}$, some FCs are selected, distributed uniformly along the GDH, for flow rate measurement. The related signal constitutes the input of the GDH system. At flow reduction in two and more FCs of one GDH down to a fixed set point, the fast acting scram signal is generated. The set point value is individual for each GDH and depends on the number of MCP in operation and on the flow rate zone of the monitored fuel channels. The GDH blockage transient is strongly affected by the position of the concerned FC in the core.

\section{NODALIZATION}

The RELAP5 nodalization of the Smolensk-3 developed by the UNIPI is divided into two parts identified as right and left sides [4]. The right side is more detailed and is considered as the damaged one. In the right side, nodalization of all the main hydraulic components of the plant are modeled. Starting from the steam drums (SDs), both are represented by a set of branches and pipes in order to reproduce the stratification that ensures the gravity-driven steam separation. The water (in the lower part) and the steam (in the upper part) zones of the SD are linked to each other by a water and steam bridge. The nozzle of the feed-water system is represented by a jet component to simulate the suction effect of these devices.

The two feed-water systems (one per each SD) are simulated by a time-dependent volume and a time-dependent junction with a nominal mass flow rate. The jet mixer components are joined to two pipes that simulate the downcomer. These two are connected to four branches that simulate the suction header. Four pipes supply the water from the suction header to four pumps, connected via other pipe components to a pressure header schematized by eight branches. Teweny-two GDH are simulated by Teweny-two pipes and, at the end of each of them, one branch is placed. Fourty-seven pipes divided into 59 volumes represent the water lines and the fuel channels, up to the connection with the steam water line, with different scaling factors ranging from 1 up to 34 . Additional 47 pipes simulate the steam water lines connected to the lower part of the SD.

The additional absorbers are simulated with a unique pipe (the same subdivision of the core channel has been 


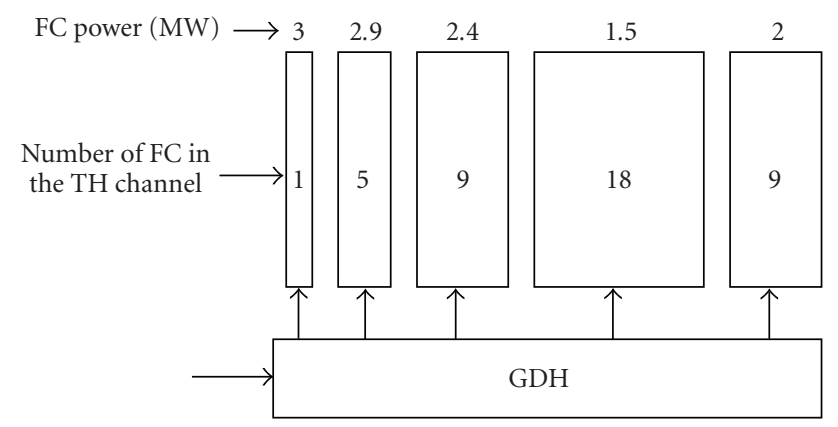

(a) Original nodalization

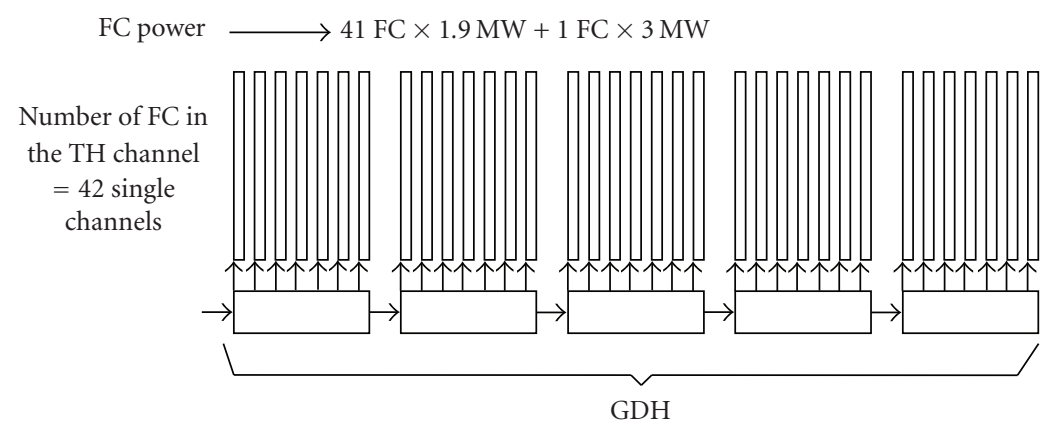

(b) Modified nodalization

Figure 2: Adopted FC power and distribution: (a) original and (b) modified GDH nodalization.

used) together with its water and steam water line. One separate circuit is reproduced to simulate the control rod (CR) and radial reflector cooling channels (one hydraulic channel for the CR cooling and one for the reflector).

For what concerns the nodalization of the thermal structure, all the passive components have the relative heat structure divided into five radial mesh points and they are considered isolated. The active structures that simulate the fuel are divided into 12 radial mesh points and into 20 axial parts. They are thermally coupled with the corresponding hydraulic volume of the core channel (left side condition). The thermal structures used to simulate the pressure tube, the graphite rings, and the graphite bricks are divided into 12 radial meshes and 24 axial parts in order to consider the axial reflector. They are thermally coupled with the core channel at the inner side and with the corresponding pipe of the reactor cavity at the outer side.

\section{RESULTS}

\subsection{Modification of the nodalization}

To investigate the mass flow oscillation phenomenon that comes out in the case of GDH blockage, the nodalization has been modified (Figure 2). The oscillations in the mass flow during the accident could not be verified when the event was simulated using the original nodalization.

Table 2 explains the main nodalization changes, namely, one (affected) GDH is schematized with its forty-two fuel channels (FCs), one by one, while the remaining GDHs have been grouped together as well as the other FCs represented by the three pipes. This choice permits the investigation of the behavior of each FC connected to the affected GDH and having a more realistic trend. To $1 \mathrm{FC}$ was attributed 3.0 MW (maximum allowed power in a FC) and for the other $41 \mathrm{FC}$ was established 1.9 MW (medium FC power).

\subsection{Consequences of the GDH blockage}

The GDH mass flow blockage scenario was calculated for Smolensk-3 NPP using the 0-D NK (neutron kinetic) model of the RELAP5 stand-alone code. In the calculation, it is assumed that there was an extreme scenario where the reactor does not shutdown. After 100 seconds of steady state calculation, the coolant flow of the GDH is suddenly blocked (see Figure 3) closing a specific valve. Consequently, as shown in Figures 4 and 5, the core flow rate in the selected channels (3.0 MW and 1.9 MW, resp.) decreases and oscillates as a result of the reactor instability. The instable behavior can affect the safe operation of the system, causing problems as mechanical vibration and thermal fatigue of components.

It is possible to verify that the mass flow rate behaves differently to the perturbation according to the attributed power to each FC. In the channel of 3.0 MW, the flow rate starts to oscillate immediately after the GDH flow stagnation (see Figure 4). However, in the channel of 1.9 MW, there is a delay of approximately 15 seconds in the oscillation starting (see Figure 5). 
TABLE 2: Main nodalization modifications.

\begin{tabular}{|c|c|c|c|}
\hline \multicolumn{2}{|c|}{ Original nodalization } & \multicolumn{2}{|r|}{ Modified nodalization } \\
\hline ID of the $22 \mathrm{GDH}$ & Number of connected channels & ID of the $2 \mathrm{GDH}$ & Number of connected channels \\
\hline 80 & $38(33+5)$ & $80(\times 21)$ & $753(400+133+220)$ \\
\hline 81 & $24(15+9)$ & 81 & 42 single channels $(41 \times 1.9 \mathrm{MW}+1 \times 3.0 \mathrm{MW})$ \\
\hline 82 & $31(18+13)$ & & \\
\hline 83 & $32(16+16)$ & & \\
\hline 84 & $37(19+18)$ & & \\
\hline 85 & $34(15+19)$ & & \\
\hline 86 & $41(18+23)$ & & \\
\hline 87 & $36(15+21)$ & & \\
\hline 88 & $43(18+25)$ & & \\
\hline 89 & $37(15+22)$ & & \\
\hline 90 & $43(18+25)$ & & \\
\hline 91 & $38(16+22)$ & & \\
\hline 92 & $43(18+25)$ & & \\
\hline 93 & $37(15+22)$ & & \\
\hline 94 & $42(9+18+5+1+9)$ & & \\
\hline 95 & $36(15+18+3)$ & & \\
\hline 96 & $39(18+21)$ & & \\
\hline 97 & $33(15+18)$ & & \\
\hline 98 & $35(18+17)$ & & \\
\hline 99 & $28(15+13)$ & & \\
\hline 100 & $28(18+10)$ & & \\
\hline \multirow[t]{2}{*}{101} & $40(34+6)$ & & \\
\hline & Total $=795$ & & Total $=795$ \\
\hline
\end{tabular}

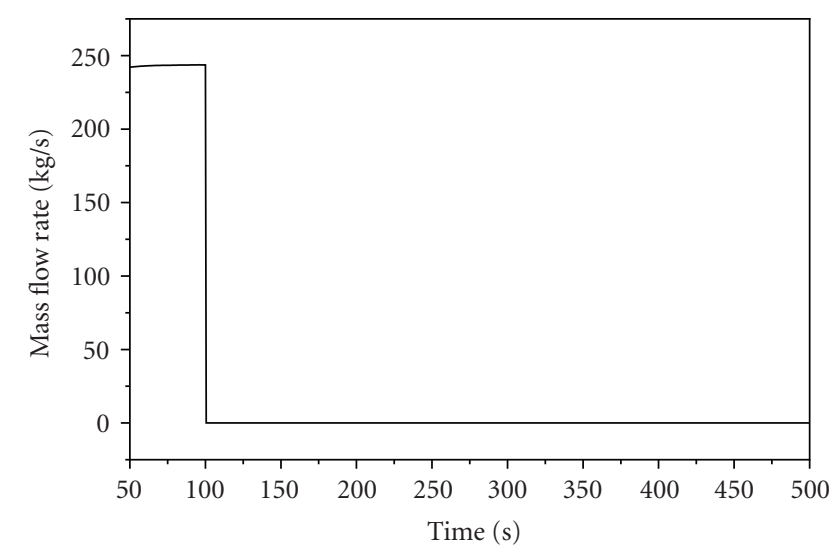

FIgURE 3: Mass flow rate at the inlet of the affected GDH.

An additional calculation was performed considering all the 42 fuel channels with 3.0 MW. In this case, as can be seen in Figure 6, there is a delay of 30 seconds for the beginning of the mass flow oscillation. Therefore, the power distribution among the FCs has significant influence on the mass flow behavior during the event. GDH coolant flow rate stagnation results in a drop of pressure in the connected channels and subsequent oscillations after the transient shown in the Figure 7.
The fuel element cladding and pressure tube (PT) walls temperatures in the FC are shown in Figures 8 and 9, respectively. In the selected channels, the fuel element cladding temperature reaches the acceptance criterion of $1200^{\circ} \mathrm{C}$ approximately at 30 seconds (to $3.0 \mathrm{MW}$ fuel channel) after flow stagnation. The acceptance criterion of pressure tube wall temperature of $650^{\circ} \mathrm{C}$ (at pressure from 4 to $8 \mathrm{MPa}$ ) is reached in, approximately, 40 seconds for the 3.0 MW FC. The overpassing of this threshold should cause the PT rupture, pressure increasing into the reactor cavity and scram generation signal.

Scram signal was not considered in the calculations because main attention was given to the investigation of the oscillatory behavior. However, in a real case, it is probably that the fuel channel of 3.0 MW could undergo first the rupture leaving the reactor to scram and safeguarding all the other $41 \mathrm{FC}$.

\section{CONCLUSIONS}

The present paper presents results of a hypothetical GDH flow rate blockage event in the Smolensk-3 RBMK. The calculation was performed using RELAP5 code model. The affected GDH was modeled with its forty-two FCs, one by one, to investigate the behavior of each FC belonging to the damaged GDH in detail. 


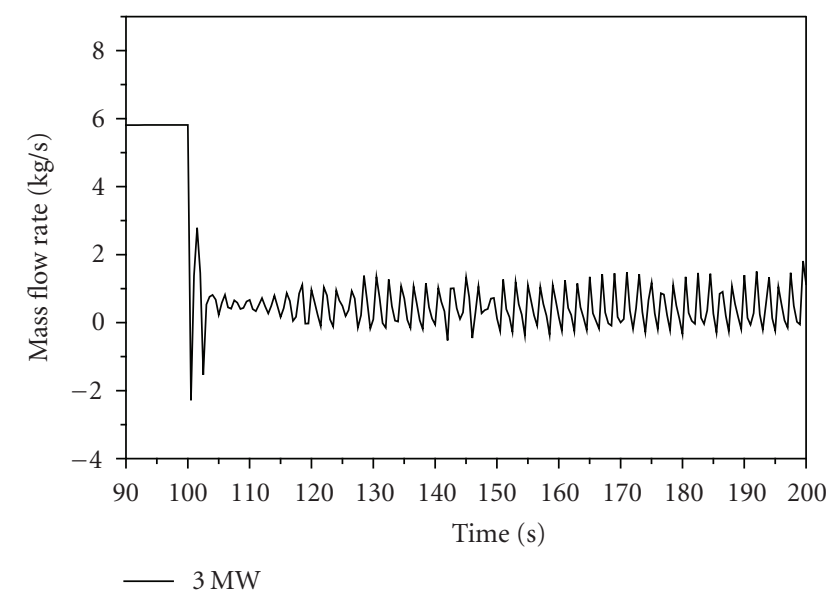

(a)

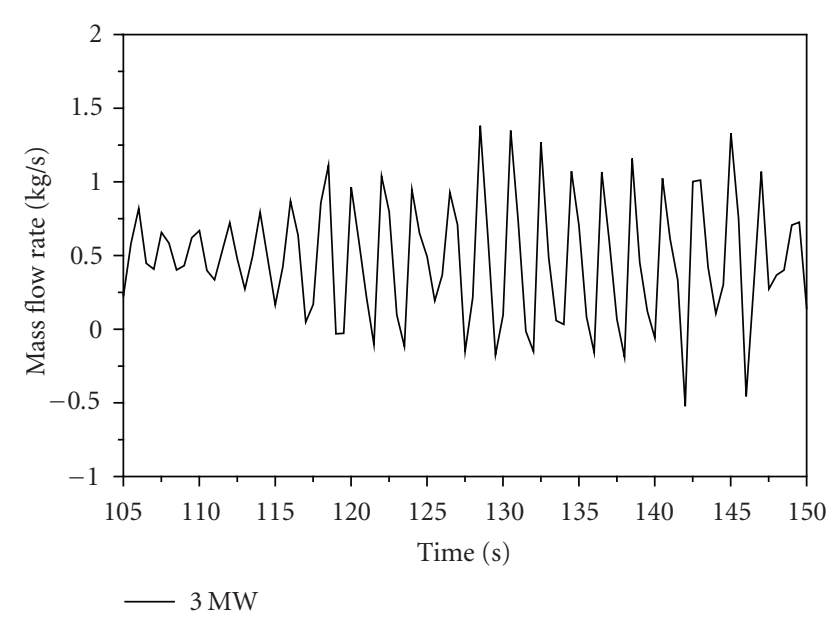

(b)

FIgURE 4: Mass flow rate evolution in a selected FC (3.0 MW). The oscillation starts immediately after the GDH flow blockage. (a) Overall transient; (b) 105 to $150 \mathrm{~s}$ time window.

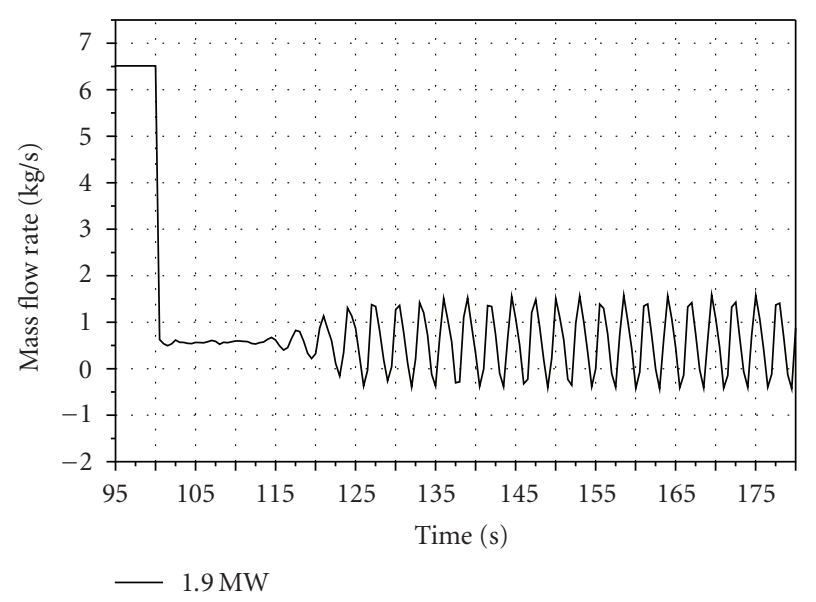

FIgURE 5: Mass flow rate evolution in a selected FC (1.9 MW). In this case, the oscillation starts approximately $15 \mathrm{~s}$ after the flow stagnation.

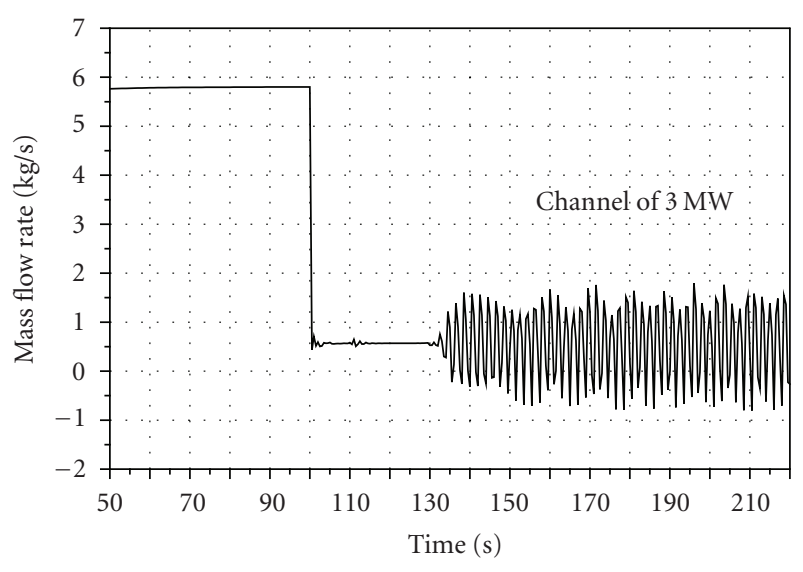

(a)

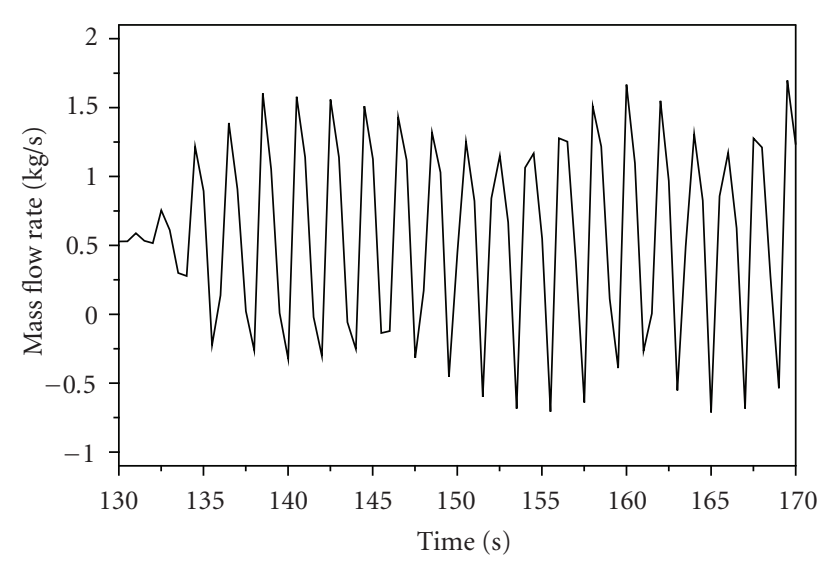

(b)

Figure 6: Mass flow rate of a selected FC. In this case, all the 42 FC have 3.0 MW of power; (a) overall transient; (b) 130 to $170 \mathrm{~s}$ time window.

In the transient simulation, after 100 seconds of steady state calculation, the coolant flow rate of the studied GDH is blocked. The calculations show that the integrity of the fuel element cladding as well as of the pressure tubes is affected if the reactor is not shutdown. In few seconds, the values of temperature reach the acceptance limits. According to the calculation results, the fuel channels at higher thermal power values undergo first the pressure tube rupture bringing the reactor to scram and safeguarding all the other FCs connected to the affected GDH.

Oscillations in the mass flow were verified in the FCs with different power values. It was observed that the start time of the oscillations depends strongly on the attributed power to each FC. In fact, the FC mass flow behaves differently to the perturbation in accordance with the power distribution established during the schematization. The instable behavior of the mass flow rate in the FCs associated with the drastic increase of temperature in the cladding during the GDH blockage affects the safe operation of the system causing mechanical vibration and thermal fatigue of components, bringing finally to the rupture of the pressure tube. 


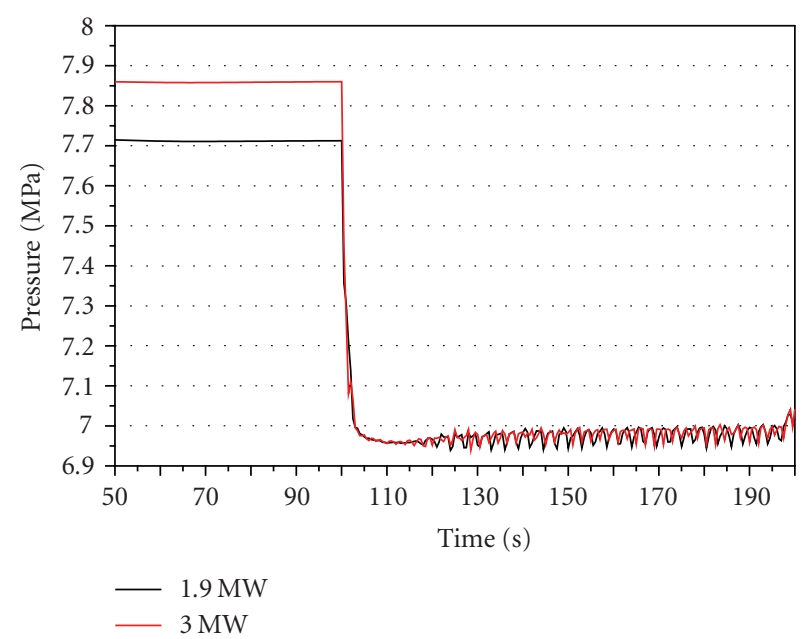

(a)

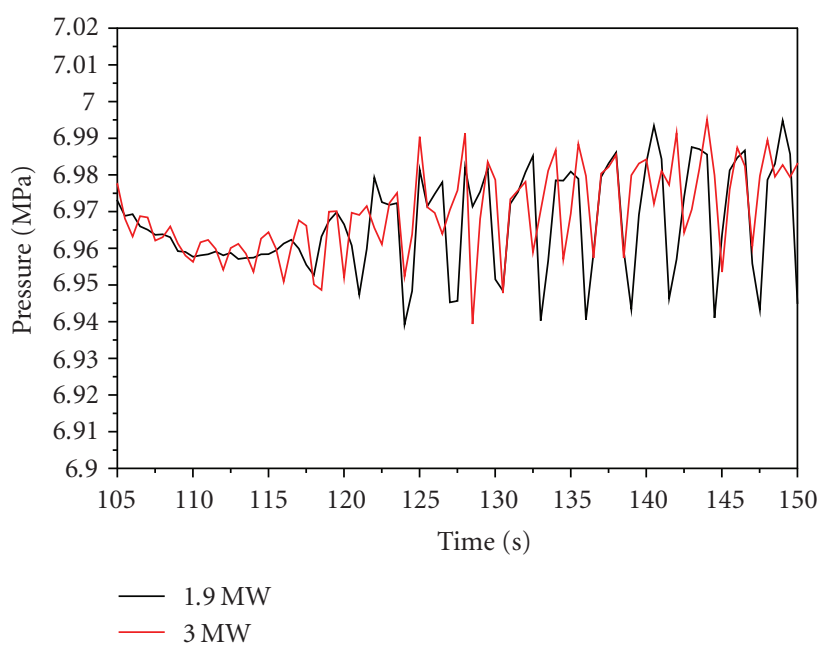

(b)

FIGURE 7: Pressure evolution in two FC; (a) overall transient; (b) 105 to 150 s time window

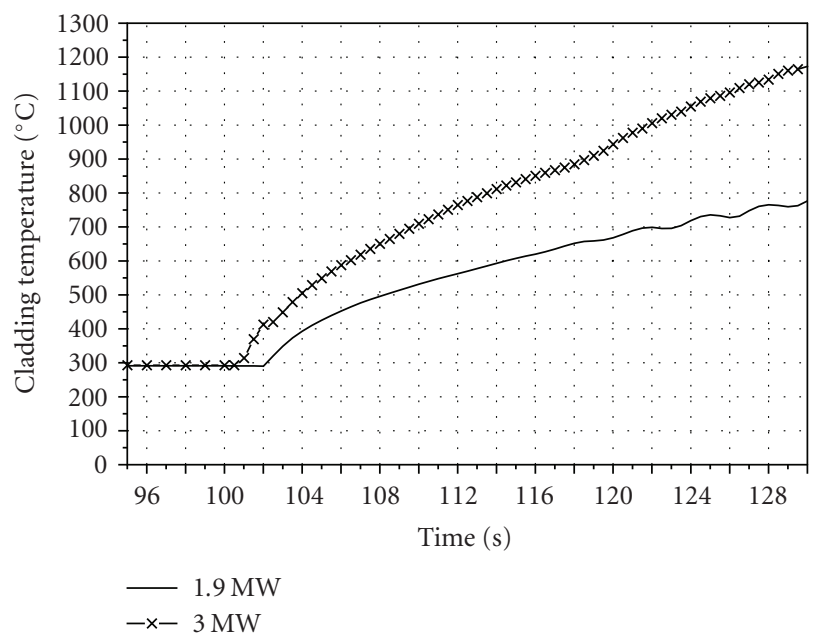

FIGURE 8: Cladding temperature evolution of two FC.

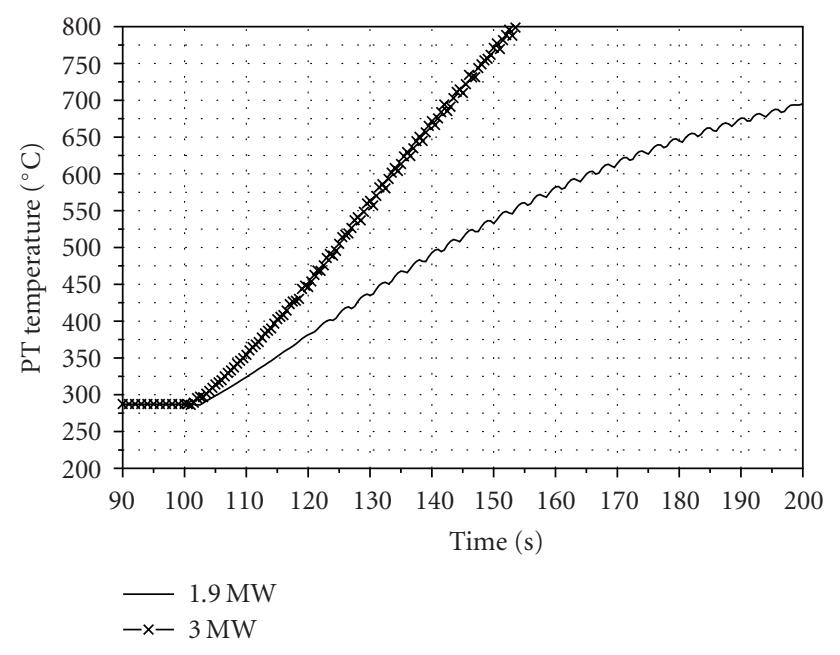

Figure 9: PT temperature evolution of two FC.

\section{REFERENCES}

[1] IAEA, "Final report of the programme on the safety of WWER and RBMK nuclear power plants," IAEA-EBP-WWER-15, International Atomic Energy Agency, Vienna, Austria, 1999.

[2] IAEA, "Accident analysis for nuclear power plants," Safety Reports Series 23, International Atomic Energy Agency, Vienna, Austria, 2002.

[3] IAEA, "Accident analysis for nuclear power plants for graphite moderated boiling water RBMK reactors," Safety Reports Series 43, International Atomic Energy Agency, Vienna, Austria, 2005.

[4] F. D'Auria, S. Soloviev, O. Novoselsky, et al., "Deterministic safety technology in RBMK, EC TACIS project R2.03/97," Final Technical Report, Part B, University of Pisa, Pisa, Italy, 2005.

[5] A. Kaliatka and E. Uspuras, "Thermal-hydraulic analysis of accidents leading to local coolant flow decrease in the main circulation circuit of RBMK-1500," Nuclear Engineering and Design, vol. 217, no. 1-2, pp. 91-101, 2002.

[6] J. E. Fisher, "RELAP5-3D model for the Kursk 1 NPP," in Proceedings of the 5th International Information Exchange Forum Safety Analysis for NPPs of VVER and RBMK Types, Obninsk, Russia, October 2000.

[7] E. Uspuras and E. Bubelis, "RELAP5-3D code validation in the neutron-dynamic analysis of transient processes taking place in RBMK-1500 reactors," Nuclear Engineering and Design, vol. 224, no. 3, pp. 293-300, 2003.

[8] E. Uspuras, A. Kaliatka, and E. Bubelis, "Validation of coupled neutronic/thermal-hydraulic code RELAP5-3D for RBMK1500 reactor analysis application," Annals of Nuclear Energy, vol. 31, no. 15, pp. 1667-1708, 2004.

[9] F. D'Auria, M. Cherubini, F. Pierro, and W. Giannotti, “The individual channel monitoring (ICM) proposal to improve the safety performance of RBMK," Nuclear Engineering and Design. In press.

\section{AUTHOR CONTACT INFORMATION}

A. Lombardi Costa: Departamento de Engenharia Nuclear, Universidade Federal de Minas Gerais (UFMG), Avenue Antônio Carlos 6627 Campus of the Universidade Federal de Minas Gerais, Prédio PCA1 Anexo Engenharia, Pampulha, CEP 31270-90, Belo Horizonte, MG, Brazil; antonella.lombardi@ing.unipi.it 
M. Cherubini: Dipartimento di Ingegneria Meccanica, Nucleare e della Produzione, Università di Pisa, Via Diotisalvi 2, 56126 Pisa, Italy; m.cherubini@ing.unipi.it

F. D'Auria: Dipartimento di Ingegneria Meccanica, Nucleare e della Produzione, Università di Pisa, Via Diotisalvi 2, 56126 Pisa, Italy; f.dauria@ing.unipi.it

W. Giannotti: Dipartimento di Ingegneria Meccanica, Nucleare e della Produzione, Università di Pisa, Via Diotisalvi 2, 56126 Pisa, Italy;w.giannotti@ing.unipi.it

A. Moskalev: N. A. Dollezhal Research and Development Institute of Power Engineering (NIKIET), P.O. Box 788, 101000 Moscow, Russia; moskalev@grpress.podolsk.ru 

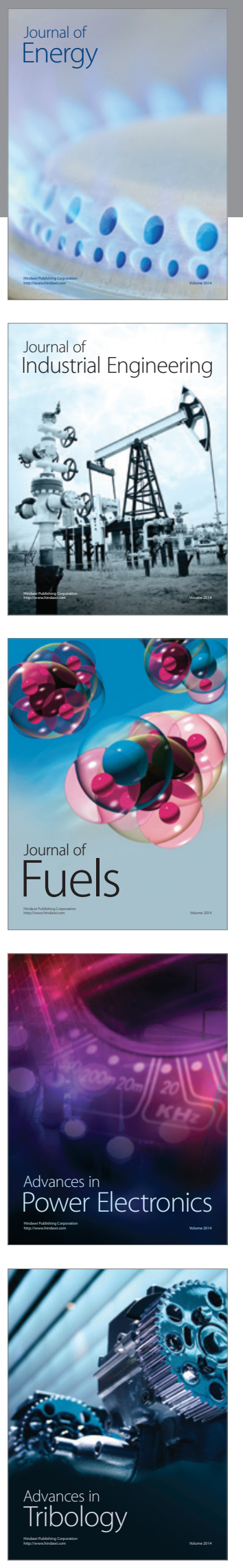
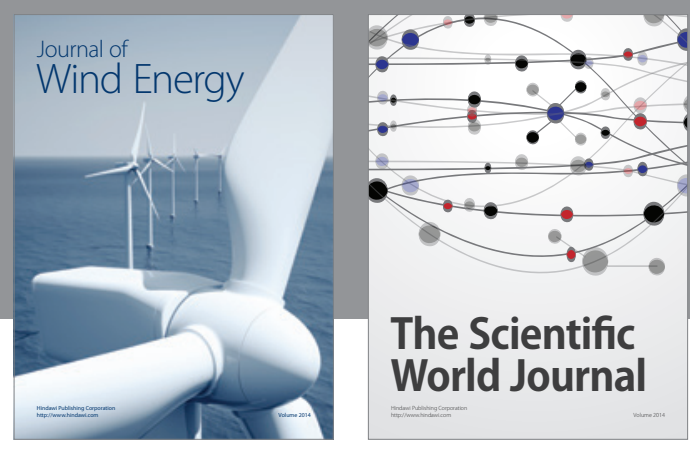

The Scientific World Journal

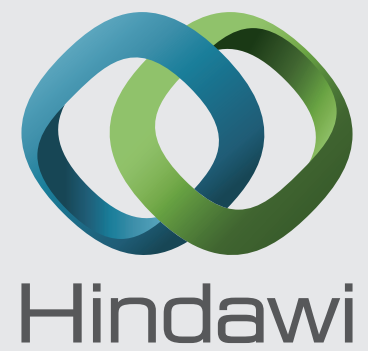

Submit your manuscripts at http://www.hindawi.com
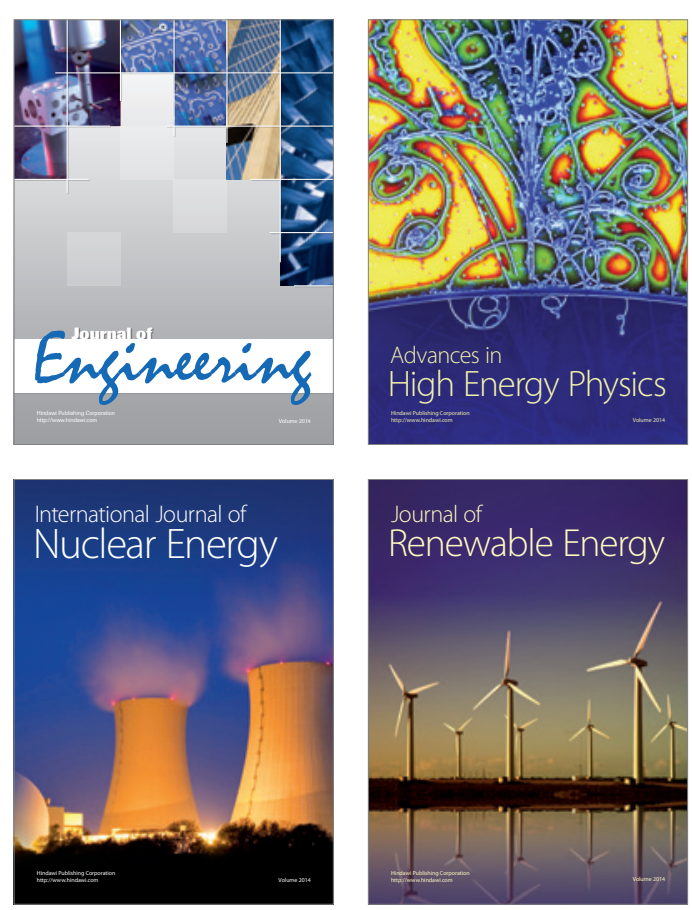

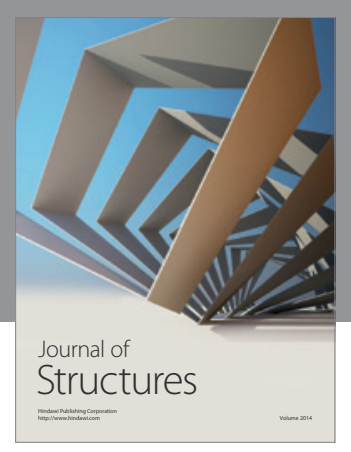

Rotating
Mechinery
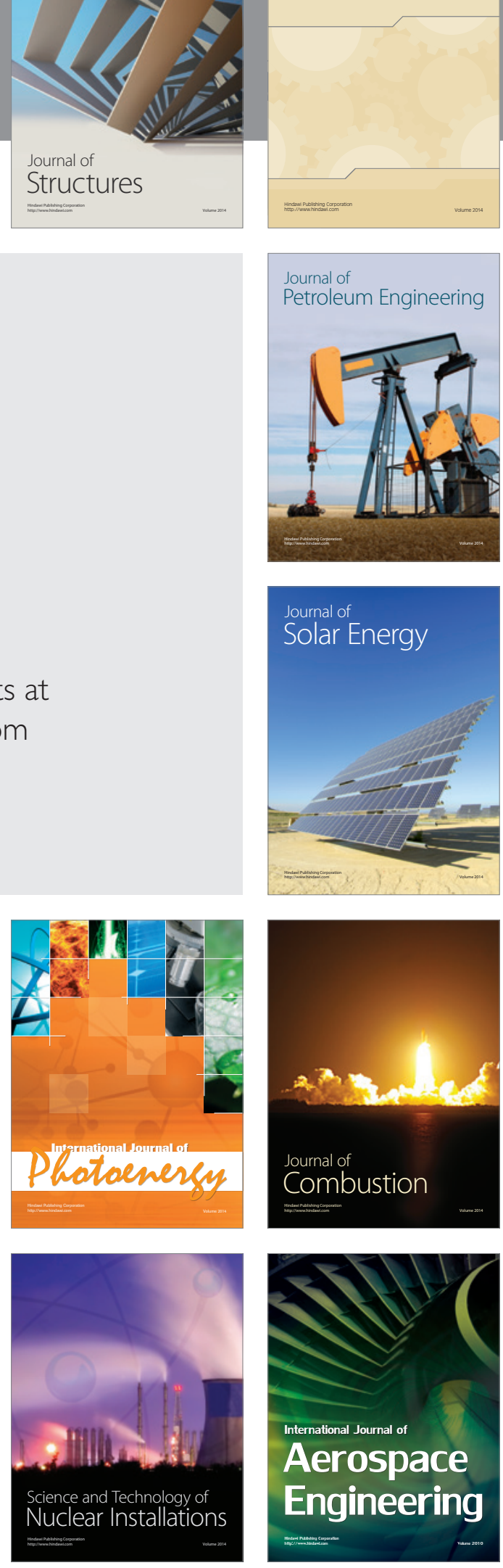